\title{
HEALTH SERVICE UTILIZATION AND REPORTED SATISFACTION AMONG ADOLESCENTS IN DEJEN DISTRICT, ETHIOPIA: A CROSS-SECTIONAL STUDY
}

\author{
Tangut Dagnew ${ }^{1}$, Fasil Tessema ${ }^{2}$, Desta Hiko ${ }^{2}$
}

\section{ABSTRACT}

BACKGROUND: There is no adequate health service or counseling specifically suitable for adolescents in Ethiopia. Adolescents' satisfaction on the health service provided is important to increase utilization and quality of care. The objective of this study was to assess health service utilization, reported satisfaction and predictors of satisfaction among adolescents of 15-19 years in Dejen District.

METHODS: A community based cross-sectional study was done from February 05 to 17, 2012. Interview method was used to collect data from 690 adolescents. Following stratification into urban and rural, six kebeles were selected by lottery method. Study participants allocated proportionally to households' size of kebele. Households were selected randomly, and one from each household was used. Descriptive measures and binary logistic regression were used to identify independent predictors for health service satisfaction.

RESULT: Among 690 adolescents, 313(45\%) used health service. Of these, 190 (60.7\%) were satisfied. Physical proximity $(A O R=3.6,95 \%$ CI: 1.8, 7.3), drug availability $(A O R=2.7,95 \%$ CI: 1.3, 5.8), health services availability $(A O R=2.5,95 \%$ CI: 1.1, 6.0), treatment in separate room (AOR=2.9, 95\% CI: 1.4 , 5.6), checked all adolescents problem (AOR=4.0, 95\% CI: 2.0, 8.5), treated with respect (AOR=3.0, 95\% CI: 1.4, 5.7) and opportunity to explain feeling (AOR=3.3, 95\% CI: 1.7, 6.6) were predictors of satisfaction.

CONCLUSION: Adolescents' health service utilization and satisfaction were low. Adolescents' perception of accessibility, acceptability and interaction with health workers' had significant influence on health services satisfaction. Therefore, health professionals and administrators should work on availing services with close proximity and acceptable behavior in order to increase adolescents' satisfaction.

KEYWORDS: Adolescent, Health service, Utilization, Satisfaction. Ethiopia

DOI: http://dx.doi.org/10.4314/ejhs.v25i1.4

\section{INTRODUCTION}

Adolescence is defined as the period between 10 and 19 years of age. It is a unique period of significant physical, cognitive and psycho-social development that brings special challenges and opportunities. Since adolescents are more mature physically than mentally or emotionally, they are engaged in many risky behaviors that may have a negative effect on their health $(1,2)$. Adolescents accounted for $18 \%$ of the world population in 2009 , in which the majority of them (88\%) lived in developing countries $(2,3)$.

The consequence of adolescents' health problem does not end in this age category; rather it may persist to their future life. Different literatures confirmed that many health problems and much of the risky behavior that underlies later health problems begin during adolescence $(4,5)$.

${ }^{1}$ East Gojjam Zonal Health Department, Amhara Regional State, Ethiopia

${ }^{2}$ Department of Epidemiology, Jimma University, Ethiopia

Corresponding Author: Tangut Dagnew, Email: tgbest2002@gmail.com 
Studies show that investing in the health of adolescents prevents the estimated 1.4 million deaths that occur globally every year (6). However, adolescents showed poorer health careseeking behavior and experienced increased community stigmatization and violence that suggests bigger challenges to them in terms of social support (7).

The majority of adolescents in Ethiopia were not utilizing reproductive health services. Concerns about confidentiality, discomfort in disclosing health concerns, absence adequate health service or counseling suitable for adolescents' and accessibility characteristics of services were some of the reasons stated by adolescents. Thus, much more intensified effort is required to increase health service utilization of adolescents especially on reproductive health service (8).

Usually, teenagers express their problems well if approached in an individualized, collaborative and negotiated manner. Thus, health services to adolescents must be delivered in an atmosphere of trust and confidentiality. Because adolescents value all aspects of privacy, health care providers should address not only informational but also psychological, social and physical privacy. This will help to successfully attract, serve and retain the young clients (9).

Satisfaction has a strong influence on the seeking of health care compliance with treatment and ongoing relationships with health care providers. Different studies listed different factors that affect adolescents' health service satisfaction. From this we conclude to effectively plan, implement or evaluate programs of care for young people is not possible without consulting the experts' young people themselves (10).

Addressing adolescents' preferences to the different attributes of health services and ensuring supportive environment from parents and relevant others would maximize the service utilization rate and satisfaction of adolescents. To increase the provision of quality health care and to help providers become skillful in addressing the sociocultural and other factors that might be important with regard to health services delivery to adolescents, we must understand adolescents' health service utilization patterns and their satisfaction on the service they receive (11).
Measuring adolescents' health service utilization and satisfaction plays an important role in the growing push towards accountability among health care providers and also can be used as an established indicator of quality of care (11). The global satisfaction factors have been well studied among adult patients but it is rare on adolescents (12).

Therefore, the finding of this study will help to target interventions to providers and the setting of health care facilities for adolescents. Knowledge on health service utilization, satisfaction and determinants of satisfaction on adolescents will enable health care administrators and providers to work on program improvements and contribute to design appropriate programs for adolescents. Therefore, the objective of this study was to assess health service utilization, perceived satisfaction and identify associated determinants of satisfaction among adolescents.

\section{METHODS AND MATERIALS}

The study was conducted in Dejen District, in East Gojjam Zone, Amhara Regional State located 226 $\mathrm{km}$ North West from Addis Ababa (13). The study was conducted from February 05 to 17, 2012. The study participants were adolescents of 15 to 19 years old who resided in the study area for at least six months.

According to the 2011/12 projection, the total population of adolescents' aged 15-19 years in Dejen District was estimated to be 12,286 . The sample size was calculated using Epi Info Version 6.04 statistical package for estimating single population proportions. We assumed 50\% proportion of health service utilization with $95 \%$ confidence level, $4 \%$ margin of error and $15 \%$ non-response to estimate the required sample size that gave a sample of 690 .

Concerning selection of kebeles, a total of 23 kebeles of the district were stratified into urban and rural. Then, six kebeles, five from rural and one from urban dwellings were selected randomly. Then, the sample size was allocated proportionally to the adolescent population size of each selected Kebele. Finally, households were selected randomly using random number generated in SPSS 16.0 version, and one adolescent from each household was selected as a study participant. For households which had more than one adolescent (15-19) years, only one was selected by lottery 
method from those who were available at home during data collection time. For households in which an adolescent was not found at home, three visits were made before considering them as not at home.

The data collectors were individuals who completed high school. Twelve data collectors were identified and recruited from kebeles which were not included in the study. Supervisors were recruited from the respective district health office staff. Two data collectors for each kebele and one supervisor for two kebeles were assigned. One day training was given for data collectors and supervisors on the objectives of the study and interviewing techniques. Pretest of the questionnaire was carried out on $5 \%$ of respondents from similar kebeles outside the study sites. During pretest, the interviewers and supervisors assessed clarity, understandability and completeness of questions and identified problems which need correction and clarification.

Considering the data collection technique (interview method) and the ability of differentiating and understanding the questions by respondents due to their literacy status, questions related to health service satisfaction were asked and measured by using three point Likert scale agreement level "agree , disagree" and "undecided" During analysis those who said undecided were considered as disagree.

The collected data were checked for completeness and consistency by supervisors during field work and rechecked again at office before data entry. Then, data were entered into SPSS 16.0 for window spreadsheet and cleaned before analysis. Descriptive statistics were used to summarize data, and bi-variate analysis was conducted to see association of variables to adolescents' health service satisfaction using chisquare test. The final model was constructed using backward stepwise logistic regression method. Variables with p-value $<0.25$ during the bi-variate analysis were entered to multivariable binary logistic regression to identify independent predictors of adolescents' health service satisfaction. P-value less than 0.05 were used to declare statistical significance in multivariable logistic analysis.

Ethical clearance and formal letter were obtained from Health Research and Postgraduate Coordinator Office of the College of Public Health and Medical Sciences, Jimma University. Written letter was obtained from Dejen Administrative Council and health office was given to kebele administrative offices and consent was confirmed from each kebele and Health Post. Informed consent was obtained from sampled adolescents after explaining the purpose of the study. Participants were assured that their names were not recorded and kept confidential and that their responses would be used only for research purpose. Participants were also informed that participation was on voluntary basis in which they could withdraw at any time if they did not want to participate in the interview.

The following operational definitions were used in the study:

Health service utilization: use of the existing modern health services in different governmental and private health facilities by adolescents for their psychological, physical and social health problems whether it is for preventive or curative purpose

Reported satisfaction: a subjective attitudinal response of adolescents in detail of their experience whether they are attaining their needs or desires on accessibility, cost of services, acceptability of health service and their interaction with health providers

Adolescents: all young people in the age group of 15-19 years (age category of old adolescents) Perceived technical competency: the subjective judgment of the patients about the professional skills and abilities of the health care provider to detect and manage their problems

Perceived interpersonal manner: adolescents' perception of interaction with the health care provider during consultation in the health care facility

\section{RESULTS}

Socio demographic characteristics of adolescent: A sample of 690 (300 males and 390 females) adolescents were interviewed. Concerning age of respondents, $432(62.6 \%)$ were between 15 to 17 years with mean age of 17 and $\mathrm{SD}=1.5$ years. The majority of the participants, 606(87.8\%), were Orthodox Christians by religion. Five hundred fifty seven $(83.6 \%)$ were single with respect to marital status and almost all respondents 685(99.3\%) were Amhara by ethnicity. Concerning educational status, 444 
(64.3\%) had primary education while $57(8.3 \%)$ were illiterate. Rural residents constituted for 554(80.3\%). Four hundred and twenty-eight $(62 \%)$ were living with both parents while $18(2.6 \%)$ of them were living alone.

Among those who were living with their father, more than half $262(54.5 \%)$ had fathers with primary education while $163(33.9 \%)$ had illiterate fathers. In the same way, 376(66.2\%) of their mothers were illiterate while $160(28.2 \%)$ had primary education. With respect to occupation, $382(79.4 \%)$ of the fathers and $434(76.4 \%)$ of mothers were farmers (Table 1).

Table 1: Socio demographic characteristics of adolescents in Dejen district, February, 2012

\begin{tabular}{|c|c|c|c|}
\hline \multicolumn{2}{|l|}{ Socio demographic characteristics } & Number of adolescents & Percent $(\%)$ \\
\hline Sex & $\begin{array}{l}\text { Female } \\
\text { Male }\end{array}$ & $\begin{array}{l}390 \\
300\end{array}$ & $\begin{array}{l}56.5 \\
43.5\end{array}$ \\
\hline Age & $\begin{array}{l}15-17 \text { year } \\
18-19 \text { year }\end{array}$ & $\begin{array}{l}432 \\
258\end{array}$ & $\begin{array}{l}62.6 \\
37.4\end{array}$ \\
\hline Marital status & $\begin{array}{l}\text { Single } \\
\text { Married } \\
\text { Divorced }\end{array}$ & $\begin{array}{l}577 \\
92 \\
21 \\
\end{array}$ & $\begin{array}{l}83.6 \\
13.3 \\
3.1 \\
\end{array}$ \\
\hline Educational status & $\begin{array}{l}\text { Elementary school } \\
\text { Secondary and } \\
\text { Above Illiterate }\end{array}$ & $\begin{array}{r}444 \\
189 \\
57\end{array}$ & $\begin{array}{c}64.3 \\
27.4 \\
8.3\end{array}$ \\
\hline Religion & $\begin{array}{l}\text { Orthodox } \\
\text { Muslim }\end{array}$ & $\begin{array}{l}606 \\
80\end{array}$ & $\begin{array}{l}87.8 \\
11.6\end{array}$ \\
\hline Ethnicity & $\begin{array}{l}\text { Amhara } \\
\text { Oromo }\end{array}$ & $\begin{array}{l}685 \\
5 \\
\end{array}$ & $\begin{array}{l}99.3 \\
0.7\end{array}$ \\
\hline Residence & $\begin{array}{l}\text { Rural } \\
\text { Urban }\end{array}$ & $\begin{array}{l}554 \\
136\end{array}$ & $\begin{array}{l}80.3 \\
19.7\end{array}$ \\
\hline With whom do you live? & $\begin{array}{l}\text { With both parents } \\
\text { With only mother } \\
\text { With other individual } \\
\text { With Only father } \\
\text { Alone }\end{array}$ & $\begin{array}{l}428 \\
127 \\
68 \\
42 \\
25\end{array}$ & $\begin{array}{l}62.0 \\
18.4 \\
9.9 \\
6.1 \\
3.6\end{array}$ \\
\hline Fathers educational status $(\mathrm{N}=481)$ & $\begin{array}{l}\text { Elementary school } \\
\text { Illiterate } \\
\text { Secondary and above }\end{array}$ & $\begin{array}{l}262 \\
163 \\
56\end{array}$ & $\begin{array}{l}54.5 \\
33.9 \\
11.6\end{array}$ \\
\hline Mothers educational status $(\mathrm{N}=568)$ & $\begin{array}{l}\text { Illiterate } \\
\text { Elementary school } \\
\text { Secondary and above }\end{array}$ & $\begin{array}{l}376 \\
160 \\
32\end{array}$ & $\begin{array}{l}66.2 \\
28.2 \\
5.6\end{array}$ \\
\hline Fathers occupation $(\mathrm{N}=481)$ & $\begin{array}{l}\text { Farmer } \\
\text { Civil servant } \\
\text { Merchant } \\
\text { Daily laborer }\end{array}$ & $\begin{array}{l}382 \\
44 \\
44 \\
11 \\
\end{array}$ & $\begin{array}{l}79.4 \\
9.2 \\
9.2 \\
2.2 \\
\end{array}$ \\
\hline Mothers occupation $(\mathrm{N}=568)$ & $\begin{array}{l}\text { Farmer } \\
\text { Housewife } \\
\text { Merchant } \\
\text { Civil servant } \\
\text { Day laborer }\end{array}$ & $\begin{array}{l}434 \\
59 \\
39 \\
19 \\
17 \\
\end{array}$ & $\begin{array}{l}76.4 \\
10.4 \\
6.9 \\
3.4 \\
3.0 \\
\end{array}$ \\
\hline $\begin{array}{l}\text { Type of Health facility visited } \\
(\mathrm{N}=313)\end{array}$ & $\begin{array}{l}\text { Health center } \\
\text { Health post } \\
\text { Private health } \\
\text { facilities* } \\
\text { Hospital }\end{array}$ & $\begin{array}{l}207 \\
49 \\
35 \\
20\end{array}$ & $\begin{array}{l}66.1 \\
15.7 \\
11.2 \\
6.4\end{array}$ \\
\hline
\end{tabular}

*Private health facilities (pharmacy and private clinic) * Other individual (other family members, non family member) 
Health Service Utilization: Among the sampled adolescents, $313(45.4 \%)$ used health services during the last one year; among these, 171(54.6\%) were in the age group 15-17 years and 188 $(60.1 \%)$ were females. With respect to marital status, 234(74.8\%) of those who used health service in the last one year were single. Similarly, from adolescents who used health service, 247(78.9\%) were urban residents.

Concerning educational status, more than half of the participants, 184(58.8\%), who visited health facility one year prior to the study period were in the category of elementary school. Literacy status of adolescents father and mother was 122(66\%) and $80(25.6 \%)$ for adolescents who used health service and lived with their single fathers and mother, respectively.

Health service utilization of adolescents varied in relation to their parents' occupation. Accordingly, 161(51.4\%) and 176(56.2\%) of the adolescents who used health service and lived with fathers and mother were farmers, respectively (Table 2).

Table 2: Socio demographic characteristics by health service utilization of adolescents in Dejen District, February, 2012

\begin{tabular}{|c|c|c|c|c|}
\hline \multirow{2}{*}{\multicolumn{2}{|c|}{ Socio demographic characteristics }} & \multicolumn{2}{|c|}{ Ever used health service } & \multirow{2}{*}{$\begin{array}{l}\text { No of adolescents } \\
\text { (690) }\end{array}$} \\
\hline & & Yes $=313$ & $\mathrm{No}=377$ & \\
\hline \multirow[t]{2}{*}{ Age } & $15-17$ year & $171(54.6)$ & $261(69.3)$ & $432(62.6)$ \\
\hline & $18-19$ year & $142(45.0)$ & $116(30.8)$ & $258(37.4)$ \\
\hline \multirow[t]{2}{*}{ Sex } & Female & $188(60.1)$ & $202(53.6)$ & $390(56.5)$ \\
\hline & Male & $125(39.9)$ & $175(46.4)$ & $300(43.5)$ \\
\hline \multirow[t]{3}{*}{ Marital status } & Single & $234(74.8)$ & $343(91)$ & $577(83.6)$ \\
\hline & Married & $65(20.8)$ & $27(7.2)$ & $92(13.3)$ \\
\hline & Divorced & $14(4.5)$ & $7(1.9)$ & $21(3.0)$ \\
\hline \multirow{3}{*}{ Educational status } & Elementary school & $184(58.8)$ & $260(69)$ & $444(64.0)$ \\
\hline & Secondary and above & $92(29.4)$ & $97(25.7)$ & $189(27.4)$ \\
\hline & Illiterate & $37(11.2)$ & $20(5.3)$ & $57(8.2)$ \\
\hline \multirow[t]{2}{*}{ Residence } & Rural & $247(78.9)$ & $307(81.4)$ & $554(80.3)$ \\
\hline & Urban & $66(21.1)$ & $70(18.6)$ & $136(19.7)$ \\
\hline \multirow[t]{3}{*}{ Father Education } & Elementary school & $94(36.0)$ & $168(44.6)$ & $262(54.5)$ \\
\hline & Secondary and Above & $28(30.0)$ & $28(7.4)$ & $56(11.6)$ \\
\hline & Illiterate & $85(27.2)$ & $78(20.7)$ & $163(33.9)$ \\
\hline \multirow[t]{3}{*}{ Mother Education } & Illiterate & $164(52.4)$ & $212(56.2)$ & $376(66.2)$ \\
\hline & Elementary school & $60(19.2)$ & $100(26.5)$ & $160(28.2)$ \\
\hline & Secondary and Above & $20(6.4)$ & $12(3.2)$ & $32(5.6)$ \\
\hline \multirow[t]{4}{*}{ Father occupation } & Farmer & $161(51.4)$ & $221(58.6)$ & $382(79.4)$ \\
\hline & Civil servant & $24(7.7)$ & $20(5.3)$ & $44(9.1)$ \\
\hline & Merchant & $19(6.1)$ & $25(6.6)$ & $44(9.1)$ \\
\hline & Day laborer & $4(1.3)$ & $7(1.9)$ & $11(2.3)$ \\
\hline \multirow[t]{5}{*}{ Mother occupation } & Farmer & $176(56.2)$ & $258(68.4)$ & $434(76.4)$ \\
\hline & Civil servant & $12(3.8)$ & $7(1.9)$ & $19(3.3)$ \\
\hline & Housewife & $29(9.3)$ & $30(8.0)$ & $59(10.4)$ \\
\hline & Merchant & $20(6.4)$ & $19(5.0)$ & $39(6.9)$ \\
\hline & Day laborer & $7(2.2)$ & $10(2.7)$ & $17(3.0)$ \\
\hline
\end{tabular}

Reasons not seeking health services: Among the participants, $377(54.6 \%)$ did not use any health service in the last one year. The main reason for not using was that there were no health problems 
that accounted for 261(69.2\%) of adolescents

(Figure1).

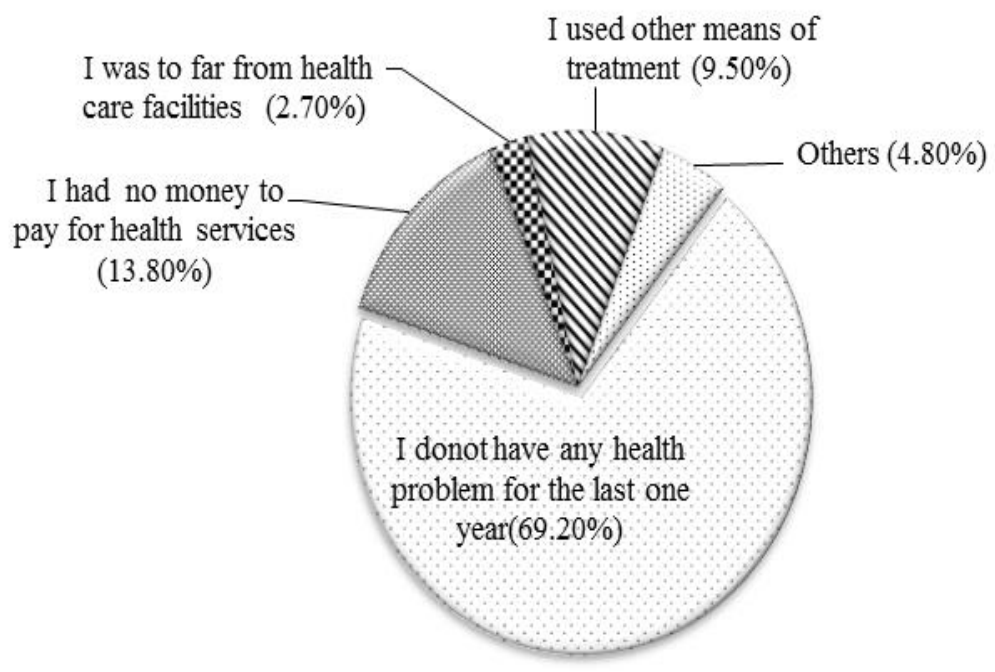

Figure 1: Reasons for not seeking health services for the last one year among adolescents in Dejen district, February, 2012

\section{Reported health service satisfaction}

Among adolescents who used health services, $190(60.7 \%)$ reported that they were satisfied with the service they received. Satisfaction was $106(62.0 \%)$ for those in the age category of $15-17$ years. In respect to sex, $78(62.4 \%)$ of males and $112(59.6 \%)$ of females were satisfied with the services they received. Satisfaction was $143(61.1 \%)$ and $41(63.1 \%)$ for single and married adolescents, respectively. Regarding residence and educational status, $41(62.1 \%)$ urban and $149(60.3 \%)$ of rural adolescents as well $22(59.5 \%)$ of illiterate and $168(61 \%)$ of those with primary education were satisfied. Satisfaction was $125(70.6 \%)$ for those who had previous health service utilization. Among those who visited health facilities for family planning, 41(75.9\%), and for illness related health services, 105(54.5\%), were satisfied. Of those who visited public health center, 140(67.6\%) were satisfied with the service they received, while for private health facilities, the corresponding figure was 20(54.1\%) (Table $3)$.

Perceived accessibility and acceptability of health services: One hundred fifty-one $(69.0 \%)$ adolescents who have proximate location to the health facilities reported satisfaction with the service they received. Similarly, 158(70\%) and $158(73.5 \%)$ of those who got drugs and were comfortable with the working hours of the health facility were satisfied, respectively. And, $123(71.3 \%)$ who were comfortable with the waiting environment of the facility, $132(71.4 \%)$ who could reach health facility easily and $173(69.8 \%)$ who got the service they want were satisfied with the service they received. With costs of health service and payment methods, $145(60.9 \%)$ who did not pay more than their ability to pay and $107(74.8 \%)$ who were comfortable with the payment method were satisfied with the service. 
Table 3: Health service and socio demographic characteristics with adolescents' health service satisfaction in Dejen District, February 2012

\begin{tabular}{|c|c|c|c|}
\hline Variables & & $\begin{array}{l}\text { Satisfaction N } \\
(\%)\end{array}$ & $\begin{array}{l}\text { Unadjusted } \\
\text { OR(95\% CI })\end{array}$ \\
\hline Age & $\begin{array}{l}15-17 \text { year } \\
18-19 \text { year }\end{array}$ & $\begin{array}{l}106(62.0) \\
84(59.2)\end{array}$ & $\begin{array}{l}1 \\
0.9(0.79,1.11)\end{array}$ \\
\hline $\operatorname{sex}$ & $\begin{array}{l}\text { Male } \\
\text { Female }\end{array}$ & $\begin{array}{l}78(62.4) \\
112(59.6)\end{array}$ & $\begin{array}{l}1.1(0.71,1.79) \\
1\end{array}$ \\
\hline Marital status & $\begin{array}{l}\text { Single } \\
\text { Married } \\
\text { Divorced }\end{array}$ & $\begin{array}{l}143(61.1) \\
41(63.1) \\
6(42.9)\end{array}$ & $\begin{array}{l}1 \\
2.1(0.72,6.21) \\
2.3(0.70,7.40)\end{array}$ \\
\hline Residence & $\begin{array}{l}\text { Urban } \\
\text { Rural }\end{array}$ & $\begin{array}{l}41(62.1) \\
149(60.3)\end{array}$ & $\begin{array}{l}1.1(0.62,1.89) \\
1\end{array}$ \\
\hline Educational status & $\begin{array}{l}\text { Illiterate } \\
\text { Primary education } \\
\text { Secondary and above }\end{array}$ & $\begin{array}{l}22(59.5) \\
109(59.2) \\
59(64.0)\end{array}$ & $\begin{array}{l}1(0.49,2.07) \\
1 \\
1.2(0.73,2.06)\end{array}$ \\
\hline Previous health service visit & $\begin{array}{l}\text { Yes } \\
\text { No }\end{array}$ & $\begin{array}{l}125(70.6) \\
65(47.8)\end{array}$ & $\begin{array}{l}1 \\
0.7(0.45,1.13)\end{array}$ \\
\hline $\begin{array}{l}\text { Type of health service } \\
\text { received }\end{array}$ & $\begin{array}{l}\text { Illness related health care } \\
\text { Family planning } \\
\text { Pregnancy related health } \\
\text { services } \\
\text { HCT testing } \\
\text { Others }\end{array}$ & $\begin{array}{l}105(54.1) \\
41(75.9) \\
11(55.0) \\
28(73.7) \\
5(71.4)\end{array}$ & $\begin{array}{l}1 \\
0.5(0.09,2.51) \\
1.3(0.22,7.3) \\
\\
0.5(0.08,3.15) \\
1.1(0.19,6.73)\end{array}$ \\
\hline Type of health facility used & $\begin{array}{l}\text { Hospital } \\
\text { Health center } \\
\text { Health posts } \\
\text { Private health facilities }\end{array}$ & $\begin{array}{l}7(35.0) \\
140(67.6) \\
23(47.0) \\
20(64.5)\end{array}$ & $\begin{array}{l}0.3(0.11,1.68) \\
1 \\
0.4(0.23,2.80) \\
0.6(0.28,1.14)\end{array}$ \\
\hline
\end{tabular}

One hundred eight $(61.7 \%)$ of the respondents who did not stay for longer time in the waiting area and 130(76.5\%) who were treated and examined in a separate room were satisfied with the health service. Similarly, 110(57.9\%) who did not stay longer time in the examination room and $138(72.6 \%)$ who accepted the number of contacts in the facility to receive services were satisfied.

In multivariate binary logistic regression analysis, distance to health facility from home showed statistically significant association on satisfaction. Accordingly, adolescents whose homes are close to the health facility were 3.6 times more likely to be satisfied $(\mathrm{AOR}=3.6,95 \% \mathrm{CI}:(1.8,7.3)$ as compared to those who were not. In the same way, presence of drugs in the health facility also determines adolescents' health service satisfaction. Adolescents who got drugs in the facility were 2.7 times more likely to be satisfied $(\mathrm{AOR}=2.7,95 \% \mathrm{CI}: 1.3,5.8)$ than those who did not. Adolescents who got the health service they want were 2.5 times more likely to be satisfied $(\mathrm{AOR}=2.5,95 \% \mathrm{CI}: 1.1,6.0)$ than those who did not. An independent predictor of health service satisfaction from perceived acceptability factor was whether adolescents' privacy was assured. Accordingly, adolescents who thought their privacy was assured were 2.9 times $(\mathrm{AOR}=2.9$, 95\% CI: $1.4,5.6)$ more likely to be satisfied than those who thought otherwise (Table 4). 
Table 4: Perceived accessibility, cost and acceptability of health service on adolescents' satisfaction in Dejen District, February, 2012

\begin{tabular}{|c|c|c|c|c|}
\hline Variables & $\begin{array}{l}\text { Satisfaction } \\
\mathbf{N}(\%)\end{array}$ & $\begin{array}{l}\text { Unadjusted } \\
\text { OR(95\%CI) }\end{array}$ & $\begin{array}{l}\text { Adjusted } \\
\text { OR(95\% CI })\end{array}$ & $\mathbf{P}$ \\
\hline \multicolumn{5}{|c|}{ Physical proximity of health facility } \\
\hline Agree & $151(69.0)$ & $3.1(1.91,5.17)^{*}$ & $3.6(1.8,7.3)^{*}$ & 0.000 \\
\hline Disagree & $39(41.5)$ & 1 & 1 & \\
\hline \multicolumn{5}{|c|}{ Convenient working hours } \\
\hline Agree & $158(70.0)$ & $3.9(2.27,6.06)^{*}$ & $2.0(0.9,4.7)$ & 0.1 \\
\hline Disagree & $32(37.2)$ & 1 & 1 & \\
\hline \multicolumn{5}{|c|}{ Drugs were Available in the facility } \\
\hline Agree & $158(73.5)$ & $5.7(3.41,9.61)^{*}$ & $2.7(1.3,5.8)^{*}$ & .009 \\
\hline Disagree & $32(32.7)$ & 1 & 1 & \\
\hline \multicolumn{5}{|c|}{ Comfortable waiting environment } \\
\hline Agree & $127(71.3)$ & $2.9(1.78,4.55)^{*}$ & $0.9(0.4,2.0)$ & 0.77 \\
\hline Disagree & $63(46.7)$ & 1 & 1 & \\
\hline \multicolumn{5}{|c|}{ No difficulty to reach facility } \\
\hline Agree & $132(70.0)$ & $3.0(1.88,4.82)^{*}$ & $0.5(0.2,1.3)$ & 0.13 \\
\hline Disagree & $58(45.3)$ & 1 & 1 & \\
\hline \multicolumn{5}{|c|}{ Got the preferred health service } \\
\hline Agree & $173(69.8)$ & $6.5(3.52,12.1)^{*}$ & $2.5(1.1,6.0)^{*}$ & 0.03 \\
\hline Disagree & $17(26.2)$ & 1 & 1 & \\
\hline \multicolumn{5}{|c|}{ Method of payment was good } \\
\hline Agree & $107(74.8)$ & $3(1.92,5.05)^{*}$ & $1.3(0.6,2.9)$ & 0.42 \\
\hline Disagree & $83(48.8)$ & 1 & 1 & \\
\hline \multicolumn{5}{|c|}{ Paid more than the ability to pay } \\
\hline Agree & $45(60.0)$ & 1 & & \\
\hline Disagree & $145(60.9)$ & $1.1(0.61,1.80)$ & NS & \\
\hline \multicolumn{5}{|c|}{ Paid more than the care received } \\
\hline Agree & $52(56.5)$ & 1 & & \\
\hline Disagree & $138(62.4)$ & $1.3(0.78,2.11)$ & NS & \\
\hline \multicolumn{5}{|c|}{$\begin{array}{l}\text { Longer waiting time before } \\
\text { examination }\end{array}$} \\
\hline Agree & $82(59.4)$ & 1 & & \\
\hline Disagree & $108(61.7)$ & $1.1(0.70,1.74)$ & NS & \\
\hline \multicolumn{5}{|c|}{ Privacy (treated in separate room) } \\
\hline Agree & $130(76.5)$ & $4.5(2.77,7.31)^{*}$ & $2.9(1.4,5.6)^{*}$ & 0.003 \\
\hline Disagree & $60(42.0)$ & 1 & 1 & \\
\hline \multicolumn{5}{|c|}{ Longer consultation time } \\
\hline Agree & $80(60.0)$ & 1 & & \\
\hline Disagree & $110(61.5)$ & $1.1(0.68,1.71)$ & NS & \\
\hline \multicolumn{5}{|c|}{$\begin{array}{l}\text { Appropriate number of contact to } \\
\text { receive }\end{array}$} \\
\hline Agree & $138(76.7)$ & $5.1(3.13,8.36)^{*}$ & $15(0.7,3.4)$ & 0.29 \\
\hline Disagree & $52(39.1)$ & 1 & 1 & \\
\hline
\end{tabular}

*indicate variables that were significant in univariate analysis at $\mathrm{p}<0.25$ and for multivariable $\mathrm{p}<0.05, \mathrm{NS}=$ Non significant in unadjusted model, $\mathrm{OR}=$ Odds ratio, $\mathrm{CI}=$ Confidence interval 
Perceived client provider interaction: Concerning interaction of adolescents with their health care providers, $112(66.7 \%)$ who had no doubt about the skills of health providers were satisfied with the service they received, and satisfaction was $165(79 \%)$ for adolescents whose problems were examined and checked in a good manner. One hundred fifty-four $(68.7 \%)$ and $160(73.7 \%)$ the respondents who were happy with

Table 5: Perceived client provider relationship on adolescents' health service satisfaction in Dejen District, February, 2012

\section{\begin{tabular}{lllll}
\hline Client provider interaction variables & Reported & Unadjusted & Adjusted OR p
\end{tabular} Satisfaction OR $(95 \% \mathrm{CI}) \quad(95 \% \mathrm{CI})$ \\ $\mathbf{N}(\%)$}

Have Doubt about skills of health provider

Agree

Disagree

Health providers examination all your problems

Agree

Disagree

Health provider had good attitude

Agree

Disagree

Confidentiality was kept

Agree

Disagree

$\mathrm{H} /$ providers were not judgmental

Agree

Disagree

H/providers minimized your fear

Agree

Disagree

Health providers were not cooperative

Agree

Disagree

Treated with respect ( Friendly)

Agree

Disagree

Protected privacy during consultation

Agree

Disagree

Health providers gave you adequate

information about your illness

Agree

Disagree

Health providers allowed to explain what

clients felt

\begin{tabular}{lllll} 
Agree & $146(81.0)$ & $8.7(5.18,14.57)^{*}$ & $3.3(1.7,6.6)^{*}$ & 0.001 \\
Disagree & $44(33.0)$ & 1 & 1 & \\
\hline
\end{tabular}

*indicate variables that were significant in univariate analysis at $\mathrm{p}<0.25, \mathrm{NS}=$ Non significant in unadjusted model, $\quad \mathrm{OR}=$ Odds ratio, $\mathrm{CI}=$ Confidence interval

\begin{tabular}{|c|c|c|c|}
\hline $78(53.8)$ & 1 & 1 & \\
\hline $112(66.7)$ & $1.7(1.12,2.71)^{*}$ & $0.9(0.5,1.9)$ & 0.85 \\
\hline $165(79.0)$ & $11.9(6.8,20.73)^{*}$ & $4.1(2,8.5)^{*}$ & .000 \\
\hline $25(24.0)$ & 1 & 1 & \\
\hline $154(68.7)$ & $3.2(1.95,5.42)^{*}$ & $0.4(0.2,1.1)$ & 0.08 \\
\hline $36(40.4)$ & 1 & 1 & \\
\hline $160(73.7)$ & $6.2(3.65,10.50)^{*}$ & $1.3(0.5,3.3)$ & 0.56 \\
\hline $30(31.3)$ & 1 & 1 & \\
\hline $133(68.2)$ & $2.3(1.42,3.74)^{*}$ & $1(0.5,2.2)$ & 0.94 \\
\hline $57(48.3)$ & 1 & 1 & \\
\hline $155(75.6)$ & $6.5(3.87,10.78)^{*}$ & $0.7(0.3,1.8)$ & 0.46 \\
\hline $35(32.4)$ & 1 & 1 & \\
\hline $82(64.0)$ & $1.3(0.82,2.02)$ & NS & \\
\hline $108(58.4)$ & 1 & & \\
\hline $155(75.3)$ & $6.3(3.71,10.44)^{*}$ & $2.9(1.4,5.7)^{*}$ & 0.003 \\
\hline $35(32.7)$ & 1 & 1 & \\
\hline $162(75.3)$ & 7.6(4.47,13.10)* & $1.1(0.4,2.7)$ & 0.92 \\
\hline $28(28.6)$ & 1 & 1 & \\
\hline
\end{tabular}

$137(74.0) \quad 4.1(2.51,6.52)^{*} \quad 1.2(0.5,2.8) \quad 0.69$

53(41.4) 11

$\begin{array}{llll}146(81.0) & 8.7(5.18,14.57)^{*} & 3.3(1.7,6.6)^{*} & 0.001\end{array}$ 
attitude of health care provider and perceived that health providers kept personal information confidential were satisfied with the service they received. Similarly, 133(68.2\%) who thought health providers were not judgmental and $155(75.6 \%)$ who were advised to minimize their worry were satisfied, respectively. Regarding communication, $187(98.4 \%)$ of the adolescents communicated with their health providers easily in local languages. Additionally, 137(74\%), $146(81 \%)$ and $162(75.3 \%)$ who got adequate information from health care providers, were allowed to explain their problem and those whose privacy was protected during communication were satisfied with the service they received, respectively.

Adolescents treated with respect and friendly, have the opportunity to explain what they felt and whether health providers checked all adolescents' health problem' during examination were Clientprovider interaction variables that have significant association with adolescents' satisfaction. Adolescents who believed that health providers examined/checked all their problems were 4 times more likely to be satisfied (AOR $=4.1,95 \% \mathrm{CI}$ : 2, 8.5) than those who did not believe so. Similarly, adolescents who were treated with respect and friendly staff were satisfied by 3 fold (AOR $=2.9$, 95\% CI: 1.4, 5.7) than those who were not. The other independent predictors which had influence on adolescents satisfaction were related to communication with health providers i.e. adolescents who were allowed to explain what they felt to their provider were 3.3 times more likely to be satisfied ( $\mathrm{AOR}=3.3,95 \% \mathrm{CI}: 1.7,6.6$ ) than those who did were not (Table 5).

\section{DISCUSSION}

The study provided information about adolescents' health service utilization and their reported satisfaction for decision makers and planners on adolescents' health services. From the finding of this study, health service utilization was low. Overall, $45.4 \%$ adolescents utilized health services in the last one year. This was less than a study done in Tanzania where $75 \%$ of adolescents used modern health services (16). The possible explanation for this difference may be the difference in socio cultural effect of population on adolescents the fact that the studies were conducted with different study participants and countries (those who were out of school and rural adolescents were not included in Tanzania). However, this is comparable with a study done in Jimma Town where $41.1 \%$ adolescents were users of reproductive health service users (8).

The proportion of adolescents' health service satisfaction was low when compared with the Tanzanian study in which $89 \%$ adolescents were satisfied (16). The possible explanation for this could be socio cultural differences of the two study areas, or there may be differences in health service delivery system to adolescents between the two countries. Similarly, this is not consistent with a study done in Switzerland where health service satisfaction rate of female adolescents was $94 \%$ (17). This discrepancy could be due to the difference in sex of the study participants (both sexes were included in this study but only females were studied in the previous one). This difference may also be due to the difference in socio cultural effect of the two study areas. Some studies showed that females were more satisfied than males (12). The low adolescents' satisfaction with the health care they received in this study showed that there were factors important but not performed when providing health service, and dealing with these factors increases their satisfaction.

In multivariable logistic analysis, perceived accessibility factors such as physical proximity of health facility, availability of drugs and presence of health services which adolescents prefer were independent predictors of adolescent health service satisfaction. This is similar with a study done in Mongolia in 2006 (18).

One hundred fifty one $(69 \%)$ of adolescents were satisfied with the physical proximity (accessibility) of the health facility to their home, and they were 3.6 times more likely to be satisfied as compared with those not comfortable. This is comparable with a study done in four West African countries (Burkina Faso, Ghana, Malawi and Uganda) where $79 \%$ of female adolescents thought that they would be able to easily access health facilities if they want (19). Other accessibility factor which had statistically significant association with adolescents' satisfaction was whether they got the service they want. In this study, $69.8 \%$ of adolescents who got the health service they want were satisfied. These 
factors were in line with WHO agreement on adolescent friendly health services (2). Among the perceived acceptability variables, privacy of health facility (treated in separate room) was significantly associated with adolescents' health service satisfaction. Accordingly, $76.5 \%$ of adolescents were satisfied because their privacy was protected. And, adolescents who thought their privacy was protected were satisfied by 2.9 times than those who did not think. This fact is supported with the study in Mongolia (18) and a qualitative study done in America by 2010 where adolescents said that they thought about their physical safety during physical examination as well as their visibility by others (20).

Independent predictors of health service satisfaction from client provider interaction variables were: adolescents who believed that their health providers examined/checked their entire health problem were 4 times more likely to be satisfied than those who did not. Similarly, a study done in Switzerland confirmed that the most important point for adolescent patient satisfaction lies in a long-term and trustworthy relationship with their health care providers (17). This indicates that increased adolescent perception on their health care provider and the way health provider approached resulted in a positive outcome on adolescents' satisfaction. In addition, $75.3 \%$ of adolescents were satisfied because they were treated with respect and friendly staff. This finding is similar with the study done in Kenya and Zimbabwe where adolescents' friendly staffs were rated as the most important for adolescents' health service satisfaction (20).

Another factor which had influence on adolescent satisfaction was their communication with health providers. Eighty-one percent of adolescents who had the opportunity to explain their problem to health providers were satisfied, and this was 3 times more likely than that of those who did not explain. This is consistent with a study done in Tanzania (16) but this finding is relatively less when compare with the study done in Switzerland where $98 \%$ of adolescents freely explained (speak) their health problem to health providers (17). The possible explanation for this difference may be related to sex of study participants (both sexes were included in this study but only females were participated in Switzerland).
In conclusion, less than half of adolescents used health service for the last one year, and the majority of them visited health facilities for illness related health care. The main reason reported for not visiting health facility within the last one year was that adolescents did not have illness. Adolescents' health service satisfaction was lowand determined by several factors which are related to accessibility, acceptability of health service and client-provider relation.

Therefore, different organizations at different levels should increase the number and strength youth friendly health service facilities, deliver services in acceptable manner and enhance the capacity of health providers how to approach adolescents. In addition, further study should be done to dig out unaddressed factors that determine satisfaction and service uses by adolescents.

\section{ACKNOWLEDGMENTS}

The authors' thanks Jimma University for financial support to this study. The authors also appreciate the study participants for their cooperation in providing the necessary information. We acknowledge the local administrators and the community for their strong support during the survey.

\section{REFERENCES}

1. UNFPA. Adolescent sexual and reproductive health toolkit for humanitarian setting: a companion to the inter-agency field manual on reproductive health in humanitarian settings. September 2009. http://www.unfpa.org/sites/default/files/pubpdf/UNFPA_ASRHtoolkit_english.pdf

2. WHO. Global consultation on adolescent friendly health services: a consensus statement. Geneva, March 7-9, 2001. www.who.int/child_adolescent_health/.../pdfs/ who_fch_cah_02.18.pdf

3. UNICEF. The state of the world's children: adolescence an age of opportunity. 2011. www.unicef.org/sowc2011/

4. WHO. Helping parents in developing countries improving adolescents'health.2007.http://whqlibdoc.who. int/publications/2007/9789241595841_eng.pd $\mathrm{f}$. 
5. Making progress: The health development and wellbeing of Australia's children and young people. Australia, Adolescent's 13-19 years, 2004-2005.

6. WHO. Strengthen the health sector response to adolescents' health and development. Department of child and adolescent health and development. 20 avenues APPIA, 1211 Geneva, Switzerland, 2009.

7. Lynn Atuyambe, Florence Mirembe, Nazarius M Tumwesigye, et al. Adolescent and adult first time mothers' health seeking practices during pregnancy and early motherhood in Wakiso District. Central Uganda, Reproductive Health 2008, 5:13.

8. Ayalew Tegegn, Yeshigeta Gelaw. Adolescent reproductive health services in Jimma city: Accessibility and utilization. Ethiop $J$ Health Science, 2009; 19:2.

9. Britto MT, Tivorsak TL, Slap GB. Adolescents' needs for health care privacy. USA. Pediatrics, 2010; 126 (6):e1469-76.

10. Rcrow A Kimber, H Gagel Storey, Shampson $\mathrm{H}$ Thomas, et al. The measurement of satisfaction with healthcare: Implications for practice from a systematic review of the literature. Health technology assessment, 2002; 6(32).3-6.

11. Karen W. Hoover, Guoyu Tao, Stuart Berman, et al. Utilization of health services in physician offices and outpatient clinics by adolescents and young women in the United States: Implications for improving access to reproductive health services. Journal of adolescent health, 2010, 46: 324-330.

12. Jeannin A, Noring F, Tschunger A, et al. Self reported health needs and use of primary health care services by adolescents enrolled in post mandatory schools or vocational training programs in Switzerland. Swiss med wkly, 2005; 135(1-2):11-8.

13. Ethiopian Road Authority. Dejen district communication office /by Ethiopian Road Authority-KAJIMA, 2008.

14. Faye,schmidt,with teresa strickland. Client satisfaction surveying:Common measurment tool. Canadaa, December, 1998.

15. Grant N. Marshall and Rond Haya. The patient satisfaction questionnaire short-form. Santa monica, Rand. 1994; ca904072138,(310):451-7002.

16. Melkiory C. Masatu, Knut-Inge Klepp, and Gunnar Kvåle. Use of health services and reported satisfaction among primary school adolescents in Arush. Tanzania, journal of adolescent health, 2001; 28:278-287.

17. Aurélie Mauerhofer, André Berthold, Christina Akré, et al. Female adolescents' views on a youth-friendly clinic: Research group on adolescent health. Institute of social and preventive medicine. University of Lausanne, Switzerland, Swiss med wkly, 2010; 140 (1-2): 18 - 23.

18. Tugs Delger Sovd, Kristin Mmari, Varia LI Povsek, et al. Acceptability as a key determinant of client satisfaction: Lessons from an evaluation of adolescent friendly health services in Mongolia. Journal of adolescent health, May 2006, 38 (5): 519-526.

19. Ann e. Biddlecom, Alister Munthali, Susheela Singh, et al. Adolescents 'views of and preferences for sexual and reproductive health services in Burkina Faso, Ghana, Malawi and Uganda. African J Reproductive health, 2007; 11(3): 99-100.

20. Maria T. Brito, anya L. Tivor sak and Gail B. slap. Adolescents need for healthcare privacy. Official journal of American academy of pediatrics, 2010; 126:6. 